\title{
How Has the Wine Sector Incorporated the Premises of Circular Economy?
}

\author{
Patricia Calicchio Berardi ${ }^{1,2}$ and Joana Maia Dias ${ }^{1}$ \\ 1. LEPABE, Department of Metallurgical and Materials Engineering, Faculty of Engineering, University of Porto, Porto 4200-465, \\ Portugal \\ 2. CELOG Centro de Excelência e Logística e Supply Chain da EAESP-FGV, São Paulo 01313-902, Brazil
}

\begin{abstract}
Much has been done in the wine production sector to promote sustainable development. Given its relevance in the economy and in society, it is fundamental to align its activities with the optimal use of resources and the regeneration and restoration of the natural system in agreement with the premises set by the Circular Economy (CE). The main interest of this work was, through a systematic literature review, to identify in the revised studies how the wine sector has incorporated the premises of CE in its activities. Six topics define the concerns addressed: water, solid waste, energy, chemical use, land use and ecosystems, in different parts of the chain: viticulture, winemaking and distribution. From the evaluation of 41 selected empirical studies, no clear definition regarding CE was found; however, the detailed analysis reveals aspects which incorporate CE practices such as the reduction of waste disposal by its treatment and recovery, the best use of resources at all stages of the process chain and the need to rethink and redesign current practices. The specific subjects identified were waste recovery, alternative energy sources such as biofuels production and water quality improvement. Land use, ecosystem impacts, and use of agrochemicals were not considered.
\end{abstract}

Key words: Wine, Circular Economy, resources, systematic review, sustainable development.

\section{Introduction}

Discussing wine production in the context of the sustainable development goals is of paramount importance, not only to contribute to improvements and developments, but also to contemplate measures necessary to reduce direct and indirect socio-environmental impacts throughout the value chain. As one of the oldest activities, wine production has a high relevance in the economic, cultural, social and environmental dynamics in several regions worldwide [1-3]. Facing the demands to align economic activities with the premises of circularity in the European market since the presentation of the Action Plan for the Circular Economy (CE) by the European Parliament in 2015 [4], it is necessary to move forward with new business models that contemplate

Corresponding author: Patricia Calicchio Berardi, Ph.D., researcher, professor and coordinator, main research field: sustainability, waste management, circular economy. the restoration and regeneration of the systems, with the exclusion of waste generation and pollution, allowing the use of resources for as long as possible. Thus, it is necessary to move beyond sustainability practices $[5,6]$.

If compared to other chains, the wine industry is considered of low environmental impact [2, 7]. However, studies show the adoption of different practices in different themes with a focus on improving environmental performance [7-11]. Although the publication of studies on sustainability and environmental performance in wine organizations has increased substantially in recent years, Christ and Burritt [2] point out that this has occurred in a disconnected way and that, overall, is underdeveloped. This indication motivated the present study in order to understand how then the insertion of the $\mathrm{CE}$ in the wine industry is presented at the present state of the research. Thus, based on systematic literature review of scientific studies, the present work aimed at 
identifying existing studies which cover this topic in the aforementioned economic segment.

\subsection{Circular Economy}

CE has aroused high interest in recent years, although it is not a new concept $[12,13]$. This is because it has become part of long-term government strategies to address the supply side problems of increasingly limited resources with the growing global demand for over-consumption and rapid disposal [12, 14]. Many of the socio-environmental issues have already been incorporated and worked on by the sustainability approach. However, what has been perceived so far is that the responses were not sufficient since the main engine of the economy is still based on a linear take-make-use-disposal model [6, 15]. The adoption of a circular model has been identified as fundamental to the achievement of the sustainable development goals $[16,17]$ and will allow socio-economic activity to be aligned with tolerable levels of access to natural resources [14].

The structuring concepts of CE are centered in the natural system, where it is known that in nature nothing is lost, nothing is created, everything is transformed and there is no waste. In other words, it is necessary to design products and services without pollution. Pollution is in agreement understood as a design error in which the resources were not correctly or completely used [18]. In addition, it is necessary to keep products and materials in use for the longest possible time, for their highest economic value. And finally, there must be regeneration of material resources and systems, both in what belongs to the so-called biological cycle as well as in the technical cycle [19-21]. Therefore, new forms of action by all the active sectors are imperative throughout all phases of the value chain. The reuse of resources, the transformation of waste into new materials and forms of energy and the restoration and regeneration of systems become inherent stages in the production processes in order to promote their greater effectiveness [22].
With the interest in aligning sectoral activities with the strategic demands of the CE Action Plan, many organizations started to contemplate new tools and new business models. For this, systematic and structural changes are required in industries and their activities to effectively reach higher levels of productivity with existing resources, in addition to the development of new technologies [23].

\subsection{Wine Production}

Every production that has in its essence agricultural practices has faced in recent times a huge number of challenges, mostly those directly related to environmental impacts [24]. Climate change has become a highly relevant issue in the agricultural sector due to the variability of temperatures in the different regions of the planet, changes in precipitation rates, the occurrence of extreme events, among others, which directly affect the productivity and quality of the production $[2,25,26]$. Both the production of grapes, which is resilient by its nature, and the respective wine production chain have worked to address the various obstacles through better environmental management practices [27]. Although wine is the result of a combination of particular elements of a micro-region (soil, climate, culture, among others), there is a worldwide concern about how this activity can help the pursuit for sustainability in the medium and long terms.

There are regulatory attention [28] and various voluntary movements $[29,30]$ to promote the best use of resources and to stimulate cultivation and production best practices. Studies highlight the concern to develop and implement different tools and technologies, throughout all stages of the wine production process [31-33]. However, many fronts (soil, water, energy, waste, local and regional impacts, logistics, materials) are equally important to be worked on. In addition, there is a difficulty in transferring findings in academic research to organizational practices, given the singular context of each study [28]. Considering the socio-economic dimension that the 
wine industry represents, the environmental impacts already felt (global reduction of production by $8 \%$ due to climatic risks [34]), which should remain in the near future, it is extremely necessary that this chain performs the business according to the assumptions of the $\mathrm{CE}$.

\section{Materials and Methods}

The paper is based on a systematic review of documents $[35,36]$. Such method of analysis brings evidence to a specific intervention based on the existing literature, using explicit and systematized search methods, careful appraisal and synthesis of the selected elements [35]. The documents were indexed in 4 databases with a large number of academic publications: (1) SCOPUS, that brings together a wide coverage with more than 22,800 titles in multiple scientific areas and subareas; (2) Web of Science (WOS) collection which has more than 18,000 high impact journals; (3) Springer Link, with 3,556 journals; and, (4) Science Direct with 3,800 journals. All databases were distributed in several scientific fields such as Life Sciences, Engineering, Mathematics and Biomedicine, among others.

The first step of the chosen research method is the definition of the research question, which was: "How has the wine sector incorporated the premises of Circular Economy?" From this point on, it was defined as the main term "CE" which was crossed with the term "Wine", in all the fields of the search engine (article title, abstract, keywords, full-text, references).

Using these criteria, a total of 618 results were found in the 4 databases (May, 2019). In Science Direct 50 papers were found, at the base of the Springer Link 108 results were listed and, in the Scopus database, plus 452 were obtained. Interestingly, the amount indicated in the WOS was only 8 publications.

As indicated in the work by Christ and Burritt [2], the highest incidence of publications on sustainability occurred after 1995. In the review of the literature on CE by Korhonen, et al. [14], works with this subject started to be published in 2007. However, the date limit of 1995 was established in the present study. It was found that the greatest emphasis of published works in our sample occurred after 2015 with the year 2018 having the greatest number of studies, as shown in Table 1.

As the interest was in scientific studies, manuscripts published as research articles and review articles have been selected, eliminating all other options such as conference manuscripts, reports, and others. Also, no selection of areas (biology, engineering, agri-food, humanities, or otherwise) was made to allow the greatest number of results.

From such criteria, a total of 230 studies were found distributed by Science Direct (31), Springer Link (27), SCOPUS (165) and WOS (7). This list was further narrowed to reduce at the SCOPUS database the results to include only those which had the word "wine" only in the main fields (title, abstract, keywords) and not in the whole text which reduced such results to 18 , therefore leading to a final selection of 83 studies. Finally, duplicates were removed leading to a final number of 72 studies for analysis, and from those, 67 results were selected by removing those with no full text available or not previously properly allocated to the type of manuscript targeted for the study (e.g. abstract, information of a special issue).

After reading the 67 abstracts, although indicated as related with $\mathrm{CE}$ and wine, it was evident that the main objective of 23 papers was not directly oriented to the production of wine and in some cases the searched terms were allocated only to the reference list of the study, or, in cases, the study was related to the area of anthropology, where the word circular was related to an aesthetic context, just as in the works of biology the association of the word circular was for a certain type of cellular structural characteristic. Further, 3 papers were eliminated because they represented 
Table 1 Research and review studies on CE at the wine industry, resulting from the systematic review.

\begin{tabular}{lll}
\hline Year & Number of papers & References \\
\hline 2019 & 8 & {$[8],[37],[38],[39],[40],[41],[42],[43]$} \\
2018 & 23 & {$[3],[7],[31],[44],[45],[46],[47],[48],[49],[50],[51],[52],[53],[54],[55],[56],[57]$,} \\
2017 & 3 & {$[58],[59],[60],[61],[62],[63]$} \\
2016 & 1 & {$[64],[65],[66]$} \\
2015 & 4 & {$[67]$} \\
2014 & 1 & {$[68],[69],[70],[71]$} \\
2013 & 1 & {$[9]$} \\
\hline
\end{tabular}
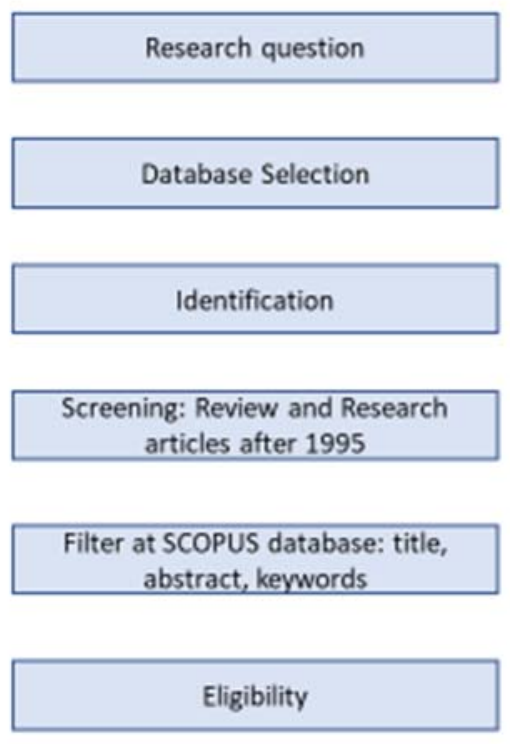

Included

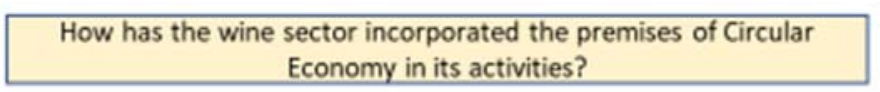

SCOPUS, Web of Science, Science Direct, Springer Link

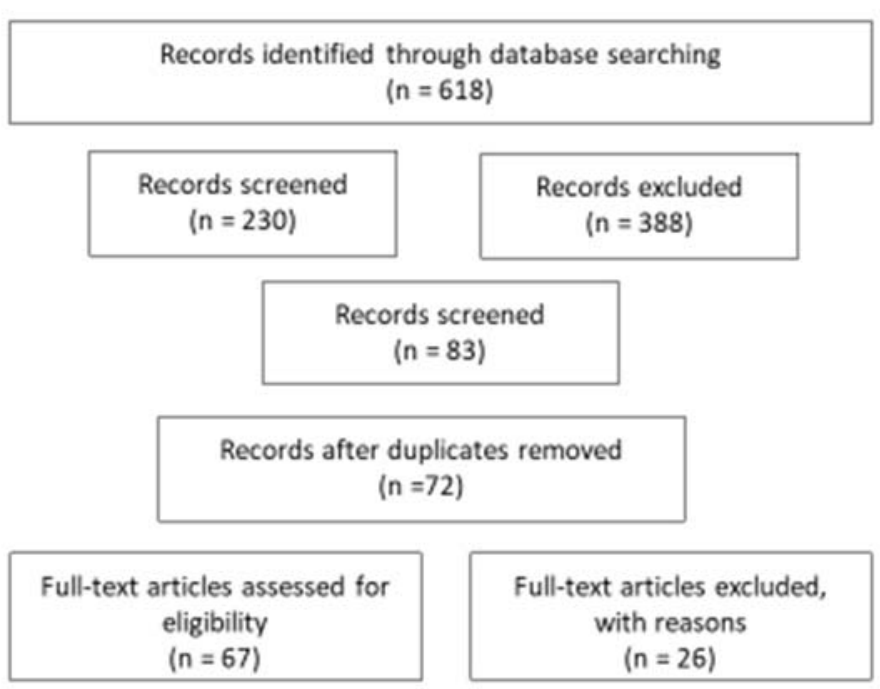

Studies included in qualitative synthesis

( $n=41)$

Fig. 1 Overview of the systematic literature review process and respective results.

Based on Schmeisser [73].

literature review. Fig. 1 presents the steps applied to the systematic review performed.

From the remaining 41 articles presented in Table 1, a framework analysis was carried out according to the subdivisions presented in the work by Christ and Burritt [2], which, after an integrative review in the wine chain for the sustainability look, the authors established six thematic divisions: water use and quality; solid waste-organic and inorganic; energy use and greenhouse gas emission; chemical use; land use; and, impact on ecosystems, in three different parts of the chain: viticulture, winemaking and distribution. However, in the reading of the articles under analysis, it was possible to identify some differences in relation to the authors' framework in the work of 2013. Of the three areas initially defined, it was verified that eight studies carried out researches focusing on supply chain without emphasizing 
viticulture or production of wine. So, this division was included in addition. The results by clipping divisions by chain area were: 7 articles in viticulture; 23 articles in winemaking; 8 articles in supply chain and 3 articles in distribution (Fig. 2).

Following the analysis, there was a new divergence about the study conducted by Christ and Burritt [2], more directly regarding the division of energy. Previously, the authors had described works focusing on carbon footprint and greenhouse gas emissions. In the current review of $\mathrm{CE}$ in the wine chain, the works that highlighted the energy theme were geared towards the generation of renewable energy through biofuels production. In addition, it was found that the studies published also addressed the waste treatment topic. That is, the energy framework of the work found contemplates not the interest in carbon footprint determination but rather the study of energy production from waste resulting from wine production.

Finally, the division of the studies by themes was reflected in the following distribution: 7 works focused on water; 10 articles brought evidence of research into energy derived from waste; 21 articles were destined to work with waste treatment and recovery; 2 studies dealt with waste treatment in conjunction with water quality, and only one study worked in the six subareas in equal degree of relevance. No work has been found that has directed efforts to land use, chemical use and the impact on ecosystems (Fig. 3).

The studies covered a wide range of different approaches, in different lines. There was a greater concern in analyzing the possible derivatives by treatment and recovery of materials through new flows, use of waste-derived resources, metrics and management indicators mainly in cases of measuring environmental impact through life cycle assessment and comparative studies between performance at different regions, individual case studies, and studies concerned with distribution packaging.

Given that the objective of this work was to identify how the theme of $\mathrm{CE}$ has been reflected in the activities of the wine sector, an evaluation was performed to access the level of depth of the studies which presented such information. From the 41 manuscripts analyzed, it was noticed that the theme of $\mathrm{CE}$ is not yet formally declared as incorporated in the actions although being pointed out as necessary for exploration in future works. However, in some cases, it was verified that even though the work did not contain the definition of $\mathrm{CE}$, the concepts are, in some

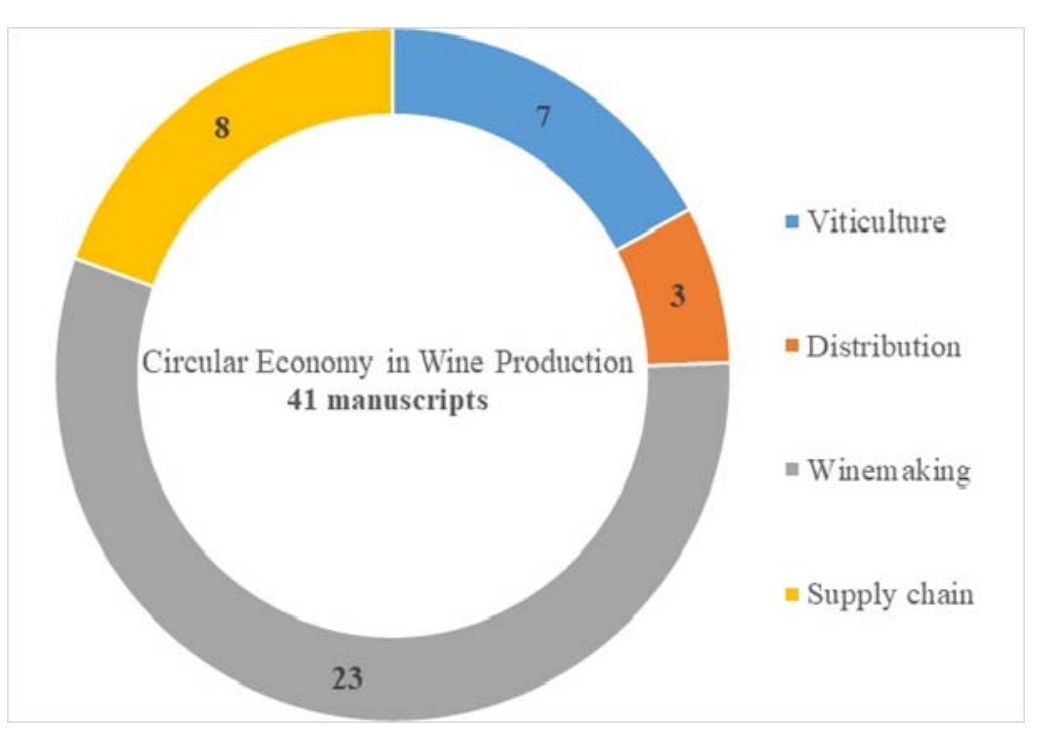

Fig. 2 Distribution by chain area divisions. 


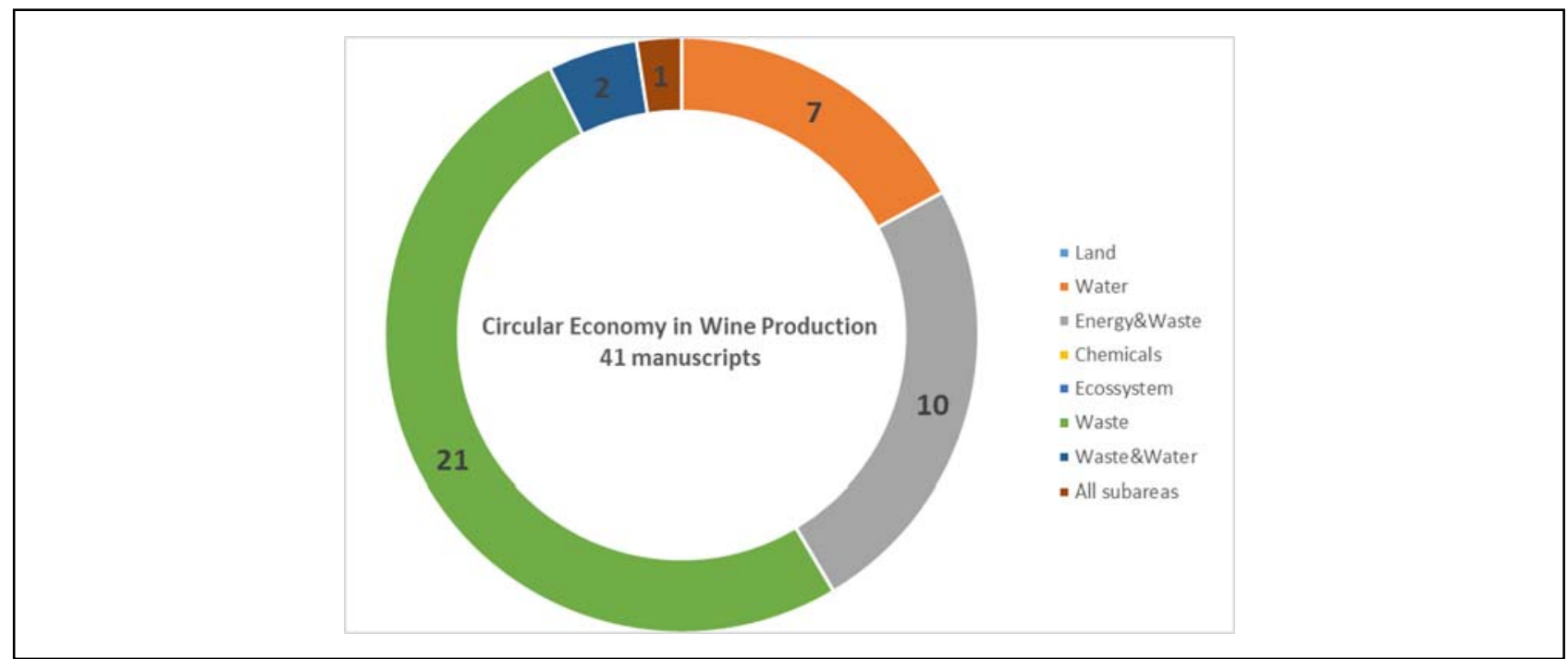

Fig. 3 Division by sustainable themes considering the present study and information adapted from Christ and Burritt [2].

way, present in the context of the work, especially in relation to the concern about reduction of waste disposal by its treatment and recovery, the best use of resources at all stages of the chain process and the need to rethink and redesign current practices taking into account sustainability aspects.

\section{Discussion and Conclusions}

CE publications are attracting interest in recent years, being a growing field, especially since 2015. In the identified sample of 41 scientific manuscripts focusing on the wine chain, the subject of circularity is not strongly defined, and, in some cases, only future research needs are indicated. In a more detailed analysis, it was possible to perceive that, although the definition of CE is not explicitly presented, its essence is inserted in the works since they contemplate the structuring elements of CE such as optimal use of resources, treatment and recovery of wastes and the revision of the production cycles, considering sustainability aspects.

The present study was interested in making a first approach to review the current scientific status concerning academic publications in the wine sector in relation to the $\mathrm{CE}$ theme. It was possible to notice that $\mathrm{CE}$ addressed to the wine industry is a transversal subject conducted by different journals, in multiple science fields. The filters applied in the systematic literature review were searched by the direct terms "CE" and "wine". Other search fields would also be relevant for analysis, which may also characterize CE. Therefore, the suggestion for future work is included in the search fields terms such as industrial symbiosis, recycling, upcycling, dematerialization, servicing, modulation, disruptive technologies and circular design to have a more broad and complete assessment. It is perceived that a vast range of aspects is yet to be studied and thus a higher number of studies covering these issues are expected in the near future, thus contributing to increasing sustainability in the wine sector.

\section{Acknowledgements}

This work was financially supported by project UID/EQU/00511/2019, Laboratory for Process Engineering, Environment, Biotechnology and Energy_LEPABE funded by national funds through FCT/MCTES (PIDDAC) and Project "LEPABE-2-ECO-INNOVATION"

-NORTE-01-0145-FEDER-000005, funded by Norte Portugal Regional Operational Programme (NORTE 2020), under PORTUGAL 2020 Partnership Agreement, through the European Regional Development Fund (ERDF). 


\section{References}

[1] Pretorius, I. S. 2000. "Tailoring Wine Yeast for the New Millennium: Novel Approaches to the Ancient Art of Winemaking." Yeast 16 (8): 675-729.

[2] Christ, K. L., and Burritt, R. L. 2013. "Critical Environmental Concerns in Wine Production: An Integrative Review." Journal of Cleaner Production 53: 232-42.

[3] Abecassis, J., Cuq, B., Escudier, J.-L., Garric, G., Kondjoyan, A., Planchot, V., et al. 2018. "Food Chains: The Cradle for Scientific Ideas and the Target for Technological Innovations." Innovative Food Science \& Emerging Technologies 46: 7-17.

[4] European Commission. 2015. Communication from the Commission to the European Parliament, the Council, the European Economic and Social Committee and the Committee of the Regions Closing the Loop-An EU Action Plan for the Circular Economy. COM (2015) 614 Final.

[5] Genovese, A., Acquaye, A. A., Figueroa, A., and Koh, S. L. 2017. "Sustainable Supply Chain Management and the Transition towards a Circular Economy: Evidence and Some Applications." Omega 66: 344-57.

[6] Ghisellini, P., Cialani, C., and Ulgiati, S. 2016. "A Review on Circular Economy: The Expected Transition to a Balanced Interplay of Environmental and Economic Systems." Journal of Cleaner Production 114: 11-32.

[7] Merli, R., Preziosi, M., and Acampora, A. 2018. "Sustainability Experiences in the Wine Sector: Toward the Development of an International Indicators System." Journal of Cleaner Production 172: 3791-805.

[8] Borsato, E., Giubilato, E., Zabeo, A., Lamastra, L., Criscione, P., Tarolli, P., et al. 2019. "Comparison of Water-Focused Life Cycle Assessment and Water Footprint Assessment: The Case of an Italian Wine." Science of The Total Environment 666: 1220-31.

[9] Naziri, E., Nenadis, N., Mantzouridou, F. T., and Tsimidou, M. Z. 2014. "Valorization of the Major Agrifood Industrial By-Products and Waste from Central Macedonia (Greece) for the Recovery of Compounds for Food Applications." Food Research International 65: $350-8$.

[10] Jradi, S., Chameeva, T. B., Delhomme, B., and Jaegler, A. 2018. "Tracking Carbon Footprint in French Vineyards: A DEA Performance Assessment." Journal of Cleaner Production 192: 43-54.

[11] Navarro, A., Puig, R., Kılıç, E., Penavayre, S., and Fullana-i-Palmer, P. 2017. "Eco-Innovation and Benchmarking of Carbon Footprint Data for Vineyards and Wineries in Spain and France." Journal of Cleaner Production 142: 1661-71.
[12] Murray, A., Skene, K., and Haynes, K. 2017. "The circular Economy: An Interdisciplinary Exploration of the Concept and Application in a Global Context." Journal of Business Ethics 140 (3): 369-80.

[13] Weetman, C. 2016. A Circular Economy Handbook for Business and Supply Chains: Repair, Remake, Redesign, Rethink. Kogan Page Publishers.

[14] Korhonen, J., Nuur, C., Feldmann, A., and Birkie, S. E. 2018. "Circular Economy as an Essentially Contested Concept.” Journal of Cleaner Production 175: 544-52.

[15] Bonviu, F. 2014. "The European Economy: From a Linear to a Circular Economy." Romanian Journal European Affairs 14: 78.

[16] Sauvé, S., Bernard, S., and Sloan, P. 2016. "Environmental Sciences, Sustainable Development and Circular Economy: Alternative Concepts for Trans-Disciplinary Research.” Environmental Development 17: 48-56.

[17] Korhonen, J., Honkasalo, A., and Seppälä, J. 2018. "Circular Economy: The Concept and Its Limitations." Ecological Economics 143: 37-46.

[18] Porter, M. E., and Van der Linde, C. 1995. "Toward a New Conception of the Environment-Competitiveness Relationship." Journal of Economic Perspectives 9 (4): 97-118.

[19] Diário da República-Resolução do Conselho de Ministros DR. 2017. Plano de Ação para a Economia Circular em Portugal (PAEC 2017:2020). No. 190-A/2017.

[20] MacArthur, E. 2013. "Towards the Circular Economy. Economic and Business Rationale for an Accelerated Transition.” Cowes, UK: Ellen MacArthur Foundation.

[21] European Environmental Agency. 2016. Circular Economy in Europe-Developing the Knowledge Base E.E. Agency

[22] McDonough, W., and Braungart, M. 2010. Cradle to Cradle: Remaking the Way We Make Things. Berkeley, CA: North Point Press.

[23] Preston, F. 2012. A Global Redesign? Shaping the Circular Economy. London: Chatham House.

[24] Food and Agriculture Organization of the United Nations. 2018. El estado de la seguridad alimentaria y la nutrición en el mundo. Fomentando la resiliencia climática en aras de la seguridad alimentaria y la nutrición. Italy. (in Spanish)

[25] Gouveia, C., Liberato, M. L. R., DaCamara, C. C., Trigo, R. M., and A.Ramos, M. 2011. "Modelling Past and Future Wine Production in the Portuguese Douro Valley." Climate Research 48 (2-3): 349-62.

[26] Mozell, M. R., and Thach, L. 2014. "The Impact of Climate Change on the Global Wine Industry: Challenges \& Solutions." Wine Economics and Policy 3 (2): 81-9.

[27] Cordano, M., Marshall, R. S., and Silverman, M. 2010. 
"How Do Small and Medium Enterprises Go 'Green'? A Study of Environmental Management Programs in the US Wine Industry." Journal of Business Ethics 92 (3): 463-78.

[28] European Commission. 2018. A Sustainable Bioeconomy for Europe: Strengthening the Connection between Economy, Society and the Environment.

[29] Delmas, M. A., and Grant, L. E. 2014. "Eco-Labeling Strategies and Price-Premium: The Wine Industry Puzzle." Business \& Society 53 (1): 6-44.

[30] Tee, E., Boland, A.-M., and Medhurst, A. 2007. "Voluntary Adoption of Environmental Management Systems in the Australian Wine and Grape Industry Depends on Understanding Stakeholder Objectives and Drivers." Australian Journal of Experimental Agriculture 47 (3): 273-83.

[31] Zambon, I., Colantoni, A., Cecchini, M., and Mosconi, E. M. 2018. "Rethinking Sustainability within the Viticulture Realities Integrating Economy, Landscape and Energy." Sustainability 10 (2): 320.

[32] Szolnoki, G. 2013. "A Cross-National Comparison of Sustainability in the Wine Industry." Journal of Cleaner Production 53: 243-51.

[33] Atkin, T., Gilinsky Jr, A., and Newton, S. K. 2012. "Environmental Strategy: Does It Lead to Competitive Advantage in the US Wine Industry?" International Journal of Wine Business Research 24 (2): 115-33.

[34] International Organisation of Vine and Wine-OIV2019. 2018 World Vitiviniculture Situation.

[35] El Bilali, H. 2018. "Transition Heuristic Frameworks in Research on Agro-Food Sustainability Transitions." Environment, Development and Sustainability: 1-36. https://doi.org/10.1007/s10668-018-0290-0.

[36] Stone, J., and Rahimifard, S. 2018. "Resilience in Agri-Food Supply Chains: A Critical Analysis of the Literature and Synthesis of a Novel Framework." Supply Chain Management: An International Journal 23 (3): 207-38.

[37] Ibn Ferjani, A., Jeguirim, M., Jellali, S., Limousy, L., Courson, C., Akrout, H., et al. 2019. "The Use of Exhausted Grape Marc to Produce Biofuels and Biofertilizers: Effect of Pyrolysis Temperatures on Biochars Properties." Renewable and Sustainable Energy Reviews 107: 425-33.

[38] León-Vaz, A., León, R., Díaz-Santos, E., Vigara, J., and Raposo, S. 2019. "Using Agro-Industrial Wastes for Mixotrophic Growth and Lipids Production by the Green Microalga Chlorella Sorokiniana." New Biotechnology 51: 31-8.

[39] Aparicio, J., Tenza-Abril, A. J., Borg, M., Galea, J., and Candela, L. 2019. "Agricultural Irrigation of Vine Crops from Desalinated and Brackish Groundwater under an
Economic Perspective. A Case Study in Siggiewi, Malta.” Science of The Total Environment 650: 734-40.

[40] Belaud, J.-P., Adoue, C., Vialle, C., Chorro, A., and Sablayrolles, C. 2019. "A Circular Economy and Industrial Ecology Toolbox for Developing an Eco-Industrial Park: Perspectives from French Policy." Clean Technologies and Environmental Policy 21 (5): 967-85.

[41] Ortiz, I., Maroño, M., Torreiro, Y., Sánchez-Hervás, J. M., Fernandez, M., and Piñeiro, R. 2019. "Strategy for the Design of Waste to Energy Processes Based on Physicochemical Characterisation." Waste and Biomass Valorization: 1-11.

[42] Oliveira, M., Costa, J. M., Fragoso, R., and Duarte, E. 2019. "Challenges for Modern Wine Production in Dry Areas: Dedicated Indicators to Preview Wastewater Flows." Water Science and Technology: Water Supply 19 (2): 653-61.

[43] Martínez Salgado, M. M., Ortega Blu, R., Janssens, M., and Fincheira, P. 2019. "Grape Pomace Compost as a Source of Organic Matter: Evolution of Quality Parameters to Evaluate Maturity and Stability.” Journal of Cleaner Production 216: 56-63.

[44] Zabaniotou, A., Kamaterou, P., Pavlou, A., and Panayiotou, C. 2018. "Sustainable Bioeconomy Transitions: Targeting Value Capture by Integrating Pyrolysis in a Winery Waste Biorefinery." Journal of Cleaner Production 172: 3387-97.

[45] Aivazidou, E., Tsolakis, N., Vlachos, D., and Iakovou, E. 2018. "A Water Footprint Management Framework for Supply Chains under Green Market Behaviour.” Journal of Cleaner Production 197: 592-606.

[46] Donia, E., Mineo, A. M., and Sgroi, F. 2018. "A Methodological Approach for Assessing Businness Investments in Renewable Resources from a Circular Economy Perspective." Land Use Policy 76: 823-7.

[47] Verotta, L., Panzella, L., Antenucci, S., Calvenzani, V., Tomay, F., Petroni, K., et al. 2018. "Fermented Pomegranate Wastes as Sustainable Source of Ellagic Acid: Antioxidant Properties, Anti-inflammatory Action, and Controlled Release under Simulated Digestion Conditions." Food Chemistry 246: 129-36.

[48] Rodríguez-Cabo, T., Rodríguez, I., Ramil, M., and Cela, R. 2018. "Assessment of Alcoholic Distillates for the Extraction of Bioactive Polyphenols from Grapevine Canes.” Industrial Crops and Products 111: 99-106.

[49] Silva, V., Igrejas, G., Falco, V., Santos, T. P., Torres, C., Oliveira, A. M. P., et al. 2018. "Chemical Composition, Antioxidant and Antimicrobial Activity of Phenolic Compounds Extracted from Wine Industry By-Products." Food Control 92: 516-22.

[50] Ligthart, T. N., Thoden van Velzen, E. U., and Brouwer, 
M. 2019. "EnvPack an LCA-Based Tool for Environmental Assessment of Packaging Chains. Part 1: Scope, Methods and Inventory of Tool." The International Journal of Life Cycle Assessment 24 (5): 900-14.

[51] Zuin, V. G., and Ramin, L. Z. 2018. "Green and Sustainable Separation of Natural Products from Agro-Industrial Waste: Challenges, Potentialities, and Perspectives on Emerging Approaches." Topics in Current Chemistry 376 (1): 3.

[52] Castro-Muñoz, R., Barragán-Huerta, B. E., Fíla, V., Denis, P. C., and Ruby-Figueroa, R. 2018. "Current Role of Membrane Technology: From the Treatment of Agro-Industrial By-Products up to the Valorization of Valuable Compounds." Waste and Biomass Valorization 9 (4): 513-29.

[53] Statuto, D., Frederiksen, P., and Picuno, P. 2018. "Valorization of Agricultural By-Products Within the 'Energyscapes': Renewable Energy as Driving Force in Modeling Rural Landscape." Natural Resources Research 28 (1): 111-24.

[54] Ait-Mouheb, N., Bahri, A., Thayer, B. B., Benyahia, B., Bourrié, G., Cherki, B., et al. 2018. "The Reuse of Reclaimed Water for Irrigation around the Mediterranean Rim: A Step towards a More Virtuous Cycle?" Regional Environmental Change 18 (3): 693-705.

[55] Tofalli, N., Loizia, P., and Zorpas, A. A. 2018. "Passengers Waste Production during Flights." Environmental Science and Pollution Research 25 (36): 35764-75.

[56] Castellar, J. A. C., Formosa, J., Fernández, A. I., Jové, P., Bosch, M. G., Morató, J., et al. 2019. "Cork as a Sustainable Carbon Source for Nature-Based Solutions Treating Hydroponic Wastewaters-Preliminary Batch Studies." Science of the Total Environment 650: 267-76.

[57] Lucarini, M., Durazzo, A., Romani, A., Campo, M., Lombardi-Boccia, G., and Cecchini, F. 2018. "Bio-Based Compounds from Grape Seeds: A Biorefinery Approach." Molecules (Basel, Switzerland) 23 (8): 1888.

[58] Esteban-Gutiérrez, M., Garcia-Aguirre, J., Irizar, I., and Aymerich, E. 2018. "From Sewage Sludge and Agri-Food Waste to VFA: Individual Acid Production Potential and Up-Scaling." Waste Management 77: 203-12.

[59] Basso, D., Weiss-Hortala, E., Patuzzi, F., Baratieri, M., and Fiori, L. 2018. "In Deep Analysis on the Behavior of Grape Marc Constituents during Hydrothermal Carbonization.” Energies 11 (6): 1379.

[60] Da Ros, C., Libralato, G., Ghirardini, A. V., Radaelli, M., and Cavinato, C. 2018. "Assessing the Potential Phytotoxicity of Digestate from Winery Wastes." Ecotoxicology and Environmental Safety 150: 26-33.
[61] Pappalardo, G., Signorello, M., and Pecorino, B. 2018. "Assessing Waste and By-Products from Wine-Growing Sector in Mt Etna." Quality-Access to Success 19: 356-62.

[62] Torrisi, S., Anastasi, E., Longhitano, S., Longo, I. C., Zerbo, A., and Borzì, G. 2018. "Circular Economy and the Benefits of Biomass as a Renewable Energy Source." Procedia Environmental Science, Engineering and Management 5 (4): 175-81.

[63] Guerini Filho, M., Lumi, M., Hasan, C., Marder, M., Leite, L. C. S., and Konrad, O. 2018. "Energy Recovery from Wine Sector Wastes: A Study about the Biogas Generation Potential in a Vineyard from Rio Grande do Sul, Brazil." Sustainable Energy Technologies and Assessments 29: 44-9.

[64] Hungría, J., Gutiérrez, M. C., Siles, J. A., and Martín, M. A. 2017. "Advantages and Drawbacks of OFMSW and Winery Waste Co-composting at Pilot Scale." Journal of Cleaner Production 164: 1050-7.

[65] Massara, T. M., Komesli, O. T., Sozudogru, O., Komesli, S., and Katsou, E. 2017. "A Mini Review of the Techno-Environmental Sustainability of Biological Processes for the Treatment of High Organic Content Industrial Wastewater Streams." Waste and Biomass Valorization 8 (5): 1665-78.

[66] Sakai, S.-i., Yano, J., Hirai, Y., Asari, M., Yanagawa, R., Matsuda, T., et al. 2017. "Waste Prevention for Sustainable Resource and Waste Management." Journal of Material Cycles and Waste Management 19 (4): 1295-313.

[67] Srivastava, V., de Araujo, A. S. F., Vaish, B., Bartelt-Hunt, S., Singh, P., and Singh, R. P. 2016. "Biological Response of Using Municipal Solid Waste Compost in Agriculture as Fertilizer Supplement." Reviews in Environmental Science and Bio/Technology 15 (4): 677-96.

[68] Yu, F., Han, F., and Cui, Z. 2015. "Evolution of Industrial Symbiosis in an Eco-Industrial Park in China." Journal of Cleaner Production 87: 339-47.

[69] Mateo, J. J., and Maicas, S. 2015. "Valorization of Winery and Oil Mill Wastes by Microbial Technologies." Food Research International 73: 13-25.

[70] Manara, P., Vamvuka, D., Sfakiotakis, S., Vanderghem, C., Richel, A., and Zabaniotou, A. 2015. "Mediterranean Agri-Food Processing Wastes Pyrolysis after Pre-treatment and Recovery of Precursor Materials: A TGA-Based Kinetic Modeling Study." Food Research International 73: 44-51.

[71] Barros, A., Gironés-Vilaplana, A., Texeira, A., Baenas, N., and Domínguez-Perles, R. 2015. "Grape stems as a Source of Bioactive Compounds: Application towards Added-Value Commodities and Significance for Human Health." Phytochemistry Reviews 14 (6): 921-31. 
[72] Ramos-de-la-Peña, A. M., Renard, C. M. G. C., Wicker, L., and Contreras-Esquivel, J. C. 2013. "Advances and Perspectives of Pachyrhizus spp. in Food Science and Biotechnology." Trends in Food Science \& Technology
29 (1): 44-54.

[73] Schmeisser, B. 2013. "A Systematic Review of Literature on Offshoring of Value Chain Activities." Journal of International Management 19 (4): 390-406. 